\title{
Contexto familiar e cumprimento da condicionalidade de frequência escolar no Programa Bolsa Família no Ceará*
}

\section{Family context and fulfillment of school attendance condition in the Bolsa Família Program in Ceará}

\author{
Domingos Abreu** \\ Jakson Alves de Aquino**
}

\begin{abstract}
RESUMO
O objetivo desta pesquisa é identificar quais características das famílias dos beneficiários do Programa Bolsa Família (PBF) exercem influência significativa sobre a probabilidade de a condicionalidade de frequência escolar ser cumprida ou não. Um banco de dados apropriado para análise quantitativa foi preparado a partir dos dados de 341 entrevistas semiestruturadas realizadas no estado do Ceará em 2016. Nossos resultados indicam que o cumprimento ou não da condicionalidade depende, principalmente, do engajamento das mães dos beneficiários nas atividades escolares dos filhos; o que, por sua vez, depende da escolaridade das mães e de seu interesse pelos estudos dos filhos.

Palavras-chave: Programa Bolsa Família. Engajamento materno. Condicionalidade. Frequência escolar.
\end{abstract}

\footnotetext{
ABSTRACT

In Brazil, low income families with children are entitled to receive a government stipend called Bolsa Família (Family Stipend), but they only receive it on condition that daily school attendance by the children is at least $85 \%$.

DOI: $10.1590 / 0104-4060.52955$

* Pesquisa financiada pelo Fundo Nacional de Desenvolvimento da Educação em parceria com a Iniciativa Educação, Pobreza e Desigualdade Social - Secretaria de Educação Continuada, Alfabetização, Diversidade e Inclusão/Ministério da Educação (Secadi/MEC).

** Universidade Federal do Ceará. Centro de Humanidades. Fortaleza, Ceará, Brasil. Av. da Universidade 2995. Benfica. CEP: 60020-181.E-mail:domingos_edu@yahoo.com.bre jaa@ufc.br
} 
The objective of this research is to identify which characteristics of the families in question have a significant effect on the probability of the school attendance condition being met. A database suitable for quantitative analysis was prepared, based on data from 341 semi-structured interviews carried out in the State of Ceará in 2016. Our results indicate that the fulfillment of the school attendance condition depends mainly on the readiness of these children's mothers to help them with homework, which, in turn, depends on the mothers' education and their involvement in school activities.

Keywords: Bolsa Família Program. Maternal commitment to child education. School Attendance Condition.

\section{Introdução}

Quando nos debruçamos sobre as relações entre o percurso escolar de "sucesso" (ou de "fracasso"), a literatura foca com frequência em quatro fatores (DE WITTE et al., 2013, p. 26-27): a) o estudante, b) sua família, c) sua escola, d) seu entorno (community factor). O presente estudo está voltado para o fator família, sendo que nos propomos a verificar em qual medida as condições domésticas são importantes para que o público beneficiário do Programa Bolsa Família (PBF) cumpra a condicionalidade de frequência escolar. Como veremos, dos fatores domésticos, destaca-se o engajamento materno na vida escolar dos filhos.

O PBF foi criado em 2004 (Lei $n^{\circ} 10.836$ ) e tem por finalidade garantir uma renda às famílias mais pobres. $\mathrm{O}$ programa tem contrapartidas em diferentes áreas a serem cumpridas pelas famílias. No que diz respeito à área da educação, exige-se uma frequência escolar mínima de $85 \%$ das crianças de 6 a 15 anos e de $75 \%$ dos adolescentes de 16 a 18 anos. Caso o estudante não consiga cumprir com a frequência exigida, a família pode ser suspensa do programa temporariamente ou mesmo perder o benefício definitivamente. O PBF tem, portanto, uma dupla face: por um lado, faz uma transferência condicionada de renda e, por outro, protege o "direito ao acesso e permanência à escolarização de crianças, adolescentes e jovens" (BRASIL, 2014a, p. 6). A contrapartida exigida das famílias é a presença escolar, que é apresentada pelo PBF, simultaneamente, como uma obrigação dos pais ou responsáveis e como um direito das crianças e adolescentes.

Para ilustrar alguns resultados da dinâmica posta em prática pelo governo federal, apresentamos aqui alguns dados do MEC sobre o "sucesso escolar" (aqui 
compreendidos como taxa de aprovação e permanência na escola) dos beneficiários quando comparados a alunos da rede pública que não são beneficiários (BRASIL, 2014a, p. 16-17).

- Sobre a aprovação: em 2012, os alunos do Ensino Fundamental da escola pública no Brasil inscritos no PBF tiveram sua taxa de aprovação próxima dos alunos não beneficiários: $85,2 \%$ e $88,2 \%$, respectivamente. No Ensino Médio, os beneficiários do PBF tiveram uma taxa de sucesso superior à dos não beneficiários: os beneficiários foram $79,7 \% \mathrm{a}$ conseguir aprovação contra $75,5 \%$ de não beneficiários.

- Sobre o abandono da escola: em 2012, no Ensino Fundamental, 2,8\% dos beneficiários abandonaram a escola, enquanto os não beneficiários foram 3,2\% a fazê-lo. Neste ano, 7,4\% dos beneficiários do Ensino Médio abandonaram os bancos escolares, número menor que os $11,3 \%$ de não beneficiários do $\mathrm{PBF}$.

Esse não foi um ano atípico. Ele é apenas o último de que temos a consolidação em mãos.

De forma mais ampla, sem tratar da frequência exigida no PBF, a bibliografia sobre a manutenção de crianças e adolescentes na escola é extensa, existindo muitos estudos e diagnósticos com propostas para o combate da evasão e do abandono escolar. Rumberger (2004) argumenta que esses dois fatores cooperam expressivamente para alterar a relação entre a idade do aluno e a série cursada, apontando que reprovação e repetência robustecem uma identificação do aluno com imagens de "fracasso" e de "ausência de inteligência", o que contribui para um abandono permanente.

Neste estudo, não tratamos simplesmente de compreender o abandono da escola, mas do que faz uma família manter as crianças e os jovens em sala de aula na frequência mínima exigida. Assim, dialogando com alguns autores que tratam de evasão e de abandono, interrogamo-nos sobre algo mais: para além de continuar na escola, o que faz uma família cumprir a condicionalidade da frequência mínima exigida?

\section{Metodologia}

Para responder a essa questão foi realizada uma pesquisa em duas etapas: uma qualitativa e outra quantitativa. A coleta de dados qualitativos foi realizada 
em parceria com os alunos da Especialização Educação Pobreza e Desigualdade Social (EPDS) durante a atividade de reflexão-ação; isto é, durante o curso de especialização houve uma disciplina voltada para a compreensão da relação da família e o universo escolar (vide PPP do curso in BRASIL, 2014b). Nessa disciplina, solicitamos que cada cursista fosse à casa de duas famílias beneficiárias do Programa Bolsa Família com filhos na escola. Cada cursista entrevistou de forma semiestruturada uma família que cumpre a condicionalidade e uma família que recebe o benefício e não consegue cumprir a condicionalidade. Os cursistas espalhados por todas as regiões do Ceará realizaram as entrevistas com famílias de seu entorno, o que nos permitiu uma amostra dos beneficiários no estado.

$\mathrm{O}$ roteiro de entrevista havia sido montado e testado junto a beneficiários do município de Maracanaú, localizado na Região Metropolitana de Fortaleza. Os cursistas foram treinados por vídeos que postamos e pelos tutores do curso, mostrando como e o porquê de utilizar a técnica da entrevista semiestruturada. Ainda lhes foi explicado a forma de realizar a entrevista e a importância do conteúdo de cada uma das perguntas feitas.

A qualidade das entrevistas muito oscilou, ora apresentando verdadeiros registros de práticas e representações familiares, ora coletando respostas monossilábicas, ou mesmo respostas induzidas pelo entrevistador. Ao final 371 áudios das entrevistas foram ouvidos por estagiários da nossa equipe de pesquisa e seus dados foram tabulados pelo uso de um formulário com questões fechadas correspondentes às questões abertas do roteiro de entrevista seguido pelos cursistas. Convertemos, assim, o conteúdo de entrevistas abertas num banco de dados que pôde ser analisado quantitativamente.

Na seção seguinte, apresentaremos as variáveis mais fortemente associadas com a nossa variável dependente, indicadora do cumprimento, ou não, da frequência escolar exigida pelo PBF.

Apontamos neste artigo as variáveis que se mostraram estatisticamente significativas para a explicação do cumprimento da condicionalidade, ou seja, quando a significância do teste do qui-quadrado $\left(\chi^{2}\right)$ foi $<0,05$. Como complemento à análise quantitativa, apresentamos trechos de entrevistas ilustrativos das situações que levam à ocorrência de associações estatísticas.

\section{Resultados}

Dos 371 áudios tabulados, em 30 não foi registrado se o beneficiário cumpria a condicionalidade, e, portanto, nas análises seguintes em que fazemos 
cruzamentos do cumprimento ou não das condicionalidades com outras variáveis, são utilizados os 341 casos que possuem esta informação ${ }^{1}$.

Como dito anteriormente, a construção de nossos dados buscou um equilíbrio entre as entrevistadas que cumprem a condicionalidade e as que não a cumprem. Assim, em nossa amostra, aproximadamente metade das respondentes se encaixam dentro do que é pedido como contrapartida pelo Programa, e metade não alcança a meta. Mais precisamente, na nossa amostra, $180(52,8 \%)$ cumprem e $160(47,2 \%)$ não cumprem a condicionalidade.

Pouco menos da metade das entrevistadas afirmam ter uma atividade remunerada $(45,8 \%)$ e a outra metade diz estar sem ocupação gratificada $(54,2 \%)$. O estudo feito por Oliveira et al. (2007) indica que a participação no PBF aumentava as chances de as pessoas entrarem no mercado de trabalho. Lembramos, no entanto, que a porcentagem de mulheres que trabalha pode ser ainda maior, considerando que entre os beneficiários existe o cuidado em não revelar fontes de recursos financeiros que possam interromper a prestação do PBF (sobretudo quando não se sabe exatamente a finalidade da pergunta que está sendo feita).

A Tabela 1 mostra outros dados relativos à família. O número de pessoas e de cômodos na casa gira em torno de cinco, o que resulta numa média de uma pessoa por cômodo. A renda advinda do PBF, em média, é de R \$211,39. O total de rendimentos da família foi perguntado, e o valor médio é apresentado na Tabela, mas alertamos que o número de "não respostas" à questão da "renda total" é muito alta (235 em 371).

TABELA 1 - DADOS DEMOGRÁFICOS E ECONÔMICOS

\begin{tabular}{|l|c|c|}
\hline \multicolumn{1}{|c|}{ Variável } & Média & Desvio padrão \\
\hline Número de pessoas na família & 4,88 & 1,90 \\
\hline Número de filhos & 2,97 & 1,60 \\
\hline Número de cômodos na residência & 4,98 & 1,42 \\
\hline Número de banheiros na residência & 0,99 & 0,38 \\
\hline Renda do Bolsa Família & 211,39 & 104,23 \\
\hline Renda total & 630,95 & 386,42 \\
\hline Renda per capita & 142,20 & 91,52 \\
\hline
\end{tabular}

FONTE: os autores (2017).

Quase metade do número de entrevistados tem até dois filhos $(46,9 \%)$, sendo que são $26,1 \%$ a terem três filhos, $11,9 \%$ a terem quatro e $16,1 \%$ com cinco ou mais filhos; o que na média equivale a 2,97 (com um desvio padrão

1 O banco de dados está disponível para download em https://dadoseteorias.wordpress.com. 
de 1,6$)$ o número de filhos. Pouco menos da metade $(48,2 \%)$ das inquiridas diz morar em uma casa com até quatro pessoas. Em torno de três quartos, em residências com até cinco pessoas $(72,6 \%)$, e o restante da amostra mora em unidades familiares que vão de 6 a 18 pessoas. Em média, as residências têm 4,88 pessoas (desvio padrão de 1,9 ), o que deixa supor a presença regular de agregados (tios, avós etc.) para além do casal (o companheiro não existe em $36,7 \%$ dos casos).

\section{Estrutura Familiar}

Dois terços das mulheres dizem viver maritalmente com um companheiro e cerca de um terço criam seus filhos sem um parceiro. A presença de um companheiro vivendo maritalmente com estas mulheres tem um impacto estatístico forte no cumprimento das condicionalidades do PBF, conforme se verifica na Tabela 2.

\section{TABELA 2 -INFLUÊNCIA DA VIDA MARITAL E DO TRABALHO INFANTO- JUVENIL NA CONDICIONALIDADE}

\begin{tabular}{|l|c|c|c|}
\hline \multicolumn{1}{|c|}{ Variável } & Não cumprem & Cumprem & Sig. do $\boldsymbol{\chi}^{2}$ \\
\hline Afirmam viver maritalmente & $55,3 \%$ & $69,4 \%$ & \multirow{2}{*}{0,007} \\
\cline { 2 - 3 } Não afirmam viver maritalmente & $44,7 \%$ & $30,6 \%$ & \\
\hline $\begin{array}{l}\text { Há menor de idade trabalhando } \\
\text { Não há menor de idade trabalhando }\end{array}$ & $9,3 \%$ & $3,9 \%$ & \multirow{2}{*}{0,042} \\
\cline { 2 - 3 } & $90,7 \%$ & $96,1 \%$ & \\
\hline
\end{tabular}

FONTE: os autores (2017).

Quando a situação marital é correlacionada com a condicionalidade, percebemos que, entre as mulheres que estão casadas, o percentual de cumprimento das condicionalidades é maior do que o de não cumprimento ( $69,4 \%$ versus $55,3 \%)$, ocorrendo o contrário entre as não casadas $(30,6 \% \text { versus } 44,7 \%)^{2}$. Poucas vezes as mulheres fizeram referência espontaneamente à ajuda dos companheiros nas tarefas escolares. Eles aparecem mais como provedores de alguma ajuda

2 Uma hipótese que não podemos testar com nossos dados é que, apesar do elevado grau de machismo de nossa sociedade, os maridos, pelo menos em situações emergenciais, podem ajudar as mulheres. Por exemplo, se normalmente uma mãe leva seus dois filhos para a escola e um deles fica doente, o pai pode, excepcionalmente, levar a criança saudável. Sem a ajuda do marido, as duas crianças ficariam em casa. 
material do que como atores que transmitem o capital escolar ("o 'Fulano', $o$ pai dele, paga o reforço para ele", ou esta outra fala: "o pai dela dá uma ajuda que dá para comprar um caderno, algum material da escola"). Lembramos que esse fenômeno também é válido quando tratamos da permanência dos filhos na escola: eles têm maior probabilidade de abandonar a escola quando moram em um lar monoparental (DE WITTE et al., 2013, p. 27). Para Carloto (2005), em sua pesquisa feita na cidade de Londrina, mulheres de baixa renda, sem um companheiro, sentem-se menos fortalecidas e às vezes "menos confiantes" pela ausência da "figura masculina dentro de casa" (CARLOTO, 2005, p. 14).

Os estudos realizados por Olsen e Farkas (1989), bem como por Marks e Fleming (1999), apontam para o abandono escolar quando o tipo de trabalho é "muito estressante". A situação em que se "trabalha para os pais" também é correlacionada com esse fenômeno (DE WITTE et al., 2013, p. 27). Campolina, Van Horn e Silveira (2013) apontam que o direcionamento precoce para o mercado de trabalho acelera o abandono da escola. A atividade laboral também tem um impacto negativo entre aqueles que permanecem na escola sem, no entanto, alcançar o cumprimento da condicionalidade. Os testemunhos de mães de famílias que não cumprem a condicionalidade dão uma ideia das diversas situações de trabalho ${ }^{3}$ :

Mãe: meu marido é agricultor, eu só recebo o bolsa família de 270 e tem uma das meninas que trabalha cuidando de uma idosa. Ela tem 14 anos. (NRM, 5F, Presença de companheiro, NC).

Mãe: só o Sicrano que vai na padaria, mais o que ele ganha é pouquinho. É "biscate", ele compra roupa pra ele, perfume. Ai eu já não conto né, porque ele já tá ficando rapaz, aí, isso aí eu não posso tirar dele. (NMR, 3F, Ausência de companheiro, NC).

Mãe: Meu marido é agricultor, trabalha no roçado com os filhos, na hora que não estão na escola. E as vezes trabalha alugado. (NRM, 5F, Presença de companheiro, NC).

3 Entre parêntesis, o local da entrevista (Região Metropolitana de Fortaleza ou não), código da escolaridade da entrevistada, status marital e cumprimento ou não da condicionalidade (C ou NC). 
A maior parte dos que trabalham encontra-se entre as famílias que não conseguem cumprir a condicionalidade: considerando todo o banco de dados, crianças e jovens trabalhadores se encontram em $6,5 \%$ dos lares, mas eles são apenas 3,9\% entre os que cumprem as condicionalidades contra $9,3 \%$ entre os que não conseguem atingir a meta do tempo mínimo exigido pelo PBF.

A literatura mostra que as famílias beneficiadas têm em geral mais filhos do que a média brasileira, mas a tendência de baixa na fecundidade parece ter sido intensificada com a entrada no Programa (ALVES; CAVENAGHI, 2013). Nossos dados não permitem fazer afirmações sobre isso, mas nos dizem que um menor número de filhos está associado a uma maior probabilidade de a família alcançar a meta esperada pelo PBF (Tabela 3). Com até dois filhos $(45,5 \%$ da amostra), as famílias enquadram-se melhor dentro do que lhes é pedido. A partir do terceiro filho, a tendência se inverte e são mais numerosas as famílias a descumprir a condicionalidade. Lembramos ainda que mais da metade de nossa amostra tem três filhos ou mais $(53,1 \%)$.

TABELA 3 -RELAÇÃO ENTRE A MATERNIDADE E O CUMPRIMENTO DA CONDICIONALIDADE

\begin{tabular}{|c|c|c|c|}
\hline Número de filhos & Não cumpre & Cumpre & Sig. do $\chi^{2}$ \\
\hline 1 & $9,3 \%$ & $17,2 \%$ & \multirow{5}{*}{0,012} \\
\hline 2 & $26,1 \%$ & $37,2 \%$ & \\
\hline 3 & $31,7 \%$ & $22,8 \%$ & \\
\hline 4 & $14,9 \%$ & $10,0 \%$ & \\
\hline $5 \mathrm{ou}+$ & $17,9 \%$ & $12,8 \%$ & \\
\hline
\end{tabular}

FONTE: os autores (2017).

Isso pode significar que as famílias numerosas têm menor probabilidade de ter o nível socioeconômico necessário para manter os filhos na escola. Não sabemos, no entanto, o real significado do impacto do número de filhos sobre a capacidade de cumprimento da condicionalidade, haja vista que, estatisticamente falando, a cada filho suplementar cresce a probabilidade de que pelo menos um deles não tenha a presença desejada na escola. Em outras palavras, considerando que cada filho de uma família numerosa tenha a mesma probabilidade de não cumprir as condicionalidades que o filho de uma família não numerosa, as mães com muitos filhos podem simplesmente ter essas probabilidades amplificadas pelo número de filhos e não por uma renda per capita menor. 


\section{Quantum de informação sobre o universo escolar}

Em outro registro da vida dessas famílias, destacamos a importância do nível de informação sobre o universo escolar como um diferencial positivo para a realização da contrapartida ao PBF. Supomos que as famílias que detêm um capital de conhecimento da escola têm um engajamento maior na educação de seus filhos. Muitas vezes, durante as entrevistas, escutamos mães relatando seu envolvimento com o "futuro da criança" ou o papel positivo ou negativo das ações da direção escolar ("a diretora está sempre presente na escola"; "nesta escola é tudo bagunçado, a diretora diz que tenta, sei lá!"). A grande maioria das mães diz conhecer a diretora da escola $(93,7 \%)$ e soube dizer se havia ou não programas de reforço na escola $(68,0 \%)$ e, entre elas, é maior o cumprimento das condicionalidades (Tabela 4).

TABELA 4 - RELAÇÃO ENTRE O CONHECIMENTO ESCOLAR E O CUMPRIMENTO DA CONDICIONALIDADE

\begin{tabular}{|l|l|l|l|}
\hline \multicolumn{1}{|c|}{ Variável } & Não cumpre & Cumpre & Sig. do $\chi^{2}$ \\
\hline Conhece o diretor da escola & $90,3 \%$ & $96,5 \%$ & \multirow{2}{*}{0,024} \\
\cline { 1 - 2 } Não conhece o diretor da escola & $9,7 \%$ & $3,5 \%$ & \\
\cline { 1 - 2 } Conhece os programas de reforço da escola & $59,2 \%$ & $73,6 \%$ & \multirow{2}{*}{0,020} \\
\cline { 1 - 3 } Não conhece os programas de reforço da escola & $40,8 \%$ & $26,4 \%$ & \\
\hline
\end{tabular}

FONTE: os autores (2017).

Estes dois depoimentos são bem emblemáticos dessa situação:

Mãe: Sim, conheço a direção... eles sempre chamam a atenção da gente, caso tiver precisando de algo, a criança, eles chegam. A gente também sempre procura eles por que as vezes a gente não cumpre o papel certo, tem que pedir desculpa, né? Que eles merecem uma resposta, né? Da gente, né? (NRM, 3M, Presença de companheiro, C).

Entrevistador: Você conhece o diretor da escola? Já conversou com ele sobre seus filhos?

Mãe: Não. Só quando ele era pequeno. (RM, 9F, Ausência de companheiro, NC). 
Quando correlacionamos esse nível de informação escolar com o cumprimento da condicionalidade, notamos que o número de famílias que consegue a frequência desejada para os filhos é maior entre as que conhecem do que entre as que são menos informadas (96,5\% versus $90,3 \%)$. Esse fenômeno pode ser observado também entre aquelas que dizem saber se a escola propõe alguma atividade extracurricular para os filhos, como nos exemplos a seguir:

Entrevistador: Na escola de seus filhos, tem algum programa que você conhece, por exemplo, Segundo Tempo ou outros Programas?

Mãe: Tem, tem várias coisas nas duas, como na creche como na escola também. (NRM, 3M, Presença de companheiro, C).

Entrevistador: Quais os programas que existem na escola que seus filhos estudam? E eles participam?

Mãe: Participa só do Mais Educação e do PROERD, e do Segundo Tempo meu menino chegou a participa ainda não. (NRM, 1M, Presença de companheiro, C).

Entrevistador: Você sabe se existe algum programa de ajuda escolar? Mãe: Acho que não. Só ensinar a estudar mesmo. Só as aulas mesmo. (NRM, 3F, Presença de companheiro, NC).

Nesse caso, a correlação entre as variáveis é ainda mais significativa, pois $59,2 \%$ das que não cumprem a condicionalidade dizem conhecer atividades extracurriculares, enquanto o percentual é de 73,6\% entre quem cumpre.

Notamos que "conhecer a professora" dos filhos não tem impacto significativo no que diz respeito à variável condicionalidade. Dito de outra forma, o conhecimento do que se passa na escola ultrapassa o simples reconhecimento da professora. Quando se conhece a professora, estamos no nível do sei que ela existe e que meus filhos estão nela e não no nível do conhecimento, que implica um investimento maior do tipo sei que ela existe, conheço seu funcionamento e sua organização. 


\section{Envolvimento na transmissão do capital escolar}

Do ponto de vista da composição do capital cultural, fruto do capital escolar, essas famílias são detentoras de pouco acúmulo doméstico (parte do capital escolar derivado da transmissão de pais para filhos). Bourdieu (1979, p. 21-22) explica que o "capital escolar" é "produto cumulado" da transmissão "feita pela família" e da transmissão "assegurada pela escola". Ele sublinha que este último componente do capital escolar é mais eficaz quando retroalimentado pelo capital cultural "diretamente herdado da família". A escolaridade das mulheres que compõem a amostra indica que $8,3 \%$ não tiveram acesso à escola, mas $74,1 \%$ passaram até cinco anos nos bancos escolares, 42,9\% concluíram o Ensino Fundamental e 21,9\%, o Ensino Médio. Registramos que apenas 2,2\% delas chegaram a ingressar em um curso superior. Olhar o que diz respeito à alfabetização formal das mães ajuda a perceber a disparidade geracional de mudança de patamar educacional, haja vista que elas são 69,1\% a indicar serem filhas de mulheres que não entraram na escola (o percentual é ainda maior no caso do avô materno, 73,9\%).

Considerando ter cursado nível médio como equivalente a 12 anos de estudo, como mostra a Tabela 5, as mães das crianças e dos adolescentes beneficiárias do PBF estudaram bem mais do que suas próprias mães. Em nossa amostra, a diferença em favor das entrevistadas é de 5,5 anos em média.

\section{TABELA 5 - ESCOLARIDADE MEDIDA EM ANOS DE ESTUDO}

\begin{tabular}{|l|c|c|}
\hline \multicolumn{1}{|c|}{ Variável } & Média & Desvio padrão \\
\hline Escolaridade da entrevistada & 7,06 & 4,02 \\
\hline Escolaridade da mãe da entrevistada & 1,59 & 3,22 \\
\hline
\end{tabular}

FONTE: os autores (2017).

As entrevistadas são, portanto, em geral, herdeiras de um baixo capital cultural doméstico tributário do capital escolar, haja vista o grande percentual de filhas de mães e pais analfabetos. O capital cultural dessas mulheres derivado do capital escolar é, em sua maior parte, não herdado dos pais. Apesar disso, o engajamento delas na atividade escolar dos filhos é estatisticamente decisivo. Quanto mais elevada sua escolaridade maior a probabilidade de as crianças cumprirem as condicionalidades (Tabela 6). 
ABREU, D.; AQUINO, J. A. de. Contexto familiar e cumprimento da condicionalidade...

TABELA 6 - RELAÇÃO ENTRE ANOS DE ESTUDO DA MÃE E CUMPRIMENTO DAS CONDICIONALIDADES (EM \%)

\begin{tabular}{|l|c|c|c|c|c|c|c|c|c|c|c|c|c|c|}
\hline $\begin{array}{l}\text { Anos na } \\
\text { escola }\end{array}$ & $\mathbf{0}$ & $\mathbf{1}$ & $\mathbf{2}$ & $\mathbf{3}$ & $\mathbf{4}$ & $\mathbf{5}$ & $\mathbf{6}$ & $\mathbf{7}$ & $\mathbf{8}$ & $\mathbf{9}$ & $\mathbf{1 0}$ & $\mathbf{1 1}$ & $\mathbf{1 2}$ & $>\mathbf{1 2}$ \\
\hline $\begin{array}{l}\text { Não } \\
\text { Cumpre }\end{array}$ & 51,9 & 68,4 & 80,0 & 53,3 & 61,1 & 61,8 & 53,1 & 22,2 & 52,9 & 51,1 & 50,0 & 18,2 & 34,4 & 28,6 \\
\hline Cumpre & 48,1 & 31,6 & 20,0 & 47,7 & 38,9 & 38,2 & 46,9 & 77,8 & 47,1 & 48,9 & 50,0 & 81,8 & 65,6 & 71,4 \\
\hline
\end{tabular}

FONTE: os autores (2017).

NOTA: (sig. $=0,034)$.

Nossos dados nos informam que 59\% do total das respondentes dizem ajudar nas tarefas escolares dos filhos, em situações como a ilustrada a seguir:

Entrevistador: Tem alguém que ajuda nas tarefas da escola?

Mãe: Não, quem ajuda sou eu. Toda vida orientei. [...] É tanto que agora, em agosto, eu vou botar a menina no reforço. Porque cada vez vai ficando mais difícil pra mim, pra mim ensinar. Como eu não tenho tanto estudo fica dificil pra mim. (RM, 7F, Presença de companheiro, C).

Dentre as que ajudam os filhos nas tarefas escolares, $53,1 \%$ não cumprem as condicionalidades e $63,9 \%$ cumprem (Tabela 7). Os percentuais maior e menor se invertem entre as que não ajudam nas tarefas, havendo um percentual maior de não cumprimento.

TABELA 7 - ENGAJAMENTO DA MÃE E SUA RELAÇÃO COM AS CONDICIONALIDADES

\begin{tabular}{|l|l|l|l|}
\hline \multicolumn{1}{|c|}{ Variável } & Não cumpre & Cumpre & Sig. do $\chi^{2}$ \\
\hline Mãe ajuda nas tarefas escolares & $53,1 \%$ & $63,9 \%$ & \multirow{2}{*}{0,054} \\
\cline { 1 - 3 } Mãe não ajuda nas tarefas escolares & $46,9 \%$ & $36,1 \%$ & \\
\cline { 1 - 3 } Alguém, além da mãe, ajuda nas tarefas escolares & $68,9 \%$ & $83,9 \%$ & \multirow{2}{*}{0,001} \\
\cline { 1 - 3 } Ninguém ajuda nas tarefas escolares & $31,1 \%$ & $16,1 \%$ & \\
\hline
\end{tabular}

FONTE: os autores (2017).

O senso prático das famílias associa, sem dúvidas, a presença das crianças na escola ao benefício recebido, mas supomos que o engajamento das mães de alguma forma motiva o próprio filho, e a literatura mostra (PITTMAN, 1991; LEE; BURKAM, 2003) que alunos são mais assíduos na escola quando se comprometem com ela. A maior escolarização das mães, quando comparada 
à geração anterior e ao esforço das mães em escolarizar seus filhos, começa a produzir resultados em famílias de baixa renda. Nossos dados apontam também para o comprometimento das mães, não somente na manutenção das crianças na escola, mas também no apoio à construção de capital escolar.

O mesmo fenômeno pode ser observado também entre aquelas famílias onde existe alguém que ajuda nos deveres escolares, mesmo que não seja a mãe. A associação entre essa variável e o cumprimento das condicionalidades é ainda maior do que quando apenas a mãe ajuda nas tarefas dos filhos (Tabela 7).

Entrevistador: Alguém da família tem escolaridade suficiente para ajudar essas crianças?

Mãe: Tem. Lá em casa quando eu não posso, meu sobrinho ajuda, minha irmã ajuda, minha mãe... Todo mundo sabe ler. (NRM, Ausência de companheiro, C).

Entrevistador: Como você se sente em ajudar os seus filhos nas tarefas escolares?

Mãe: Eu me sinto muito mal meio que impotente, porque eu não sei e as vezes, acontece do meu filho me perguntar alguma coisa e eu não sei respon$\operatorname{der}$ [voz trêmula, emocionada]. (NRM, 0, Ausência de companheiro, NC).

Vale lembrar que a probabilidade de cumprir a condicionalidade aumenta quando o trabalho de inculcação dos saberes escolares é mais intenso. As mães que melhor executam essa tarefa obtêm um maior grau de sucesso.

\section{Considerações finais}

A título de sinopse do que foi apresentado, indicamos de forma resumida o que se segue.

Primeiramente destacamos que as famílias das entrevistadas são compostas de cerca de cinco pessoas, das quais três são filhos. Em dois terços das famílias, existe a presença de um companheiro junto à mãe. Esta situação de vida marital aparece como significativa do ponto de vista estatístico. Talvez, as "pequenas fendas abertas" em direção à autonomia das mulheres produzidas na estrutura de dominação masculina, descritas por Leão Rego e Pinzani (2014, p. 201), não 
sejam ainda suficientes para igualar mulheres com e sem um companheiro no quesito cumprimento da condicionalidade escolar.

Em seguida, podemos dizer que em condições de vida no limite da pobreza, a gerência dos filhos é mais fácil quando nenhum deles trabalha (o que, como dito no texto, vale também para a evasão e o abandono). A "alta natalidade", para usar a expressão de Leão Rego e Pinzani (2014, p. 188), também tem impacto estatístico significativo no cumprimento da condicionalidade: quanto maior o número de filhos menores as chances dessas famílias estarem em conformidade com o que é solicitado pelo PBF.

O capital de informação sobre o universo escolar adverte sobre a competência de estar em dia com a frequência exigida. As mães que melhor conhecem esse universo têm mais chances de seus filhos realizarem carreiras escolares bem-sucedidas. Conhecer o diretor ou a diretora da escola é mais importante que saber o nome da professora dos filhos. Quer dizer que elas minimamente sabem do funcionamento do estabelecimento, quem o dirige e quais são as regras. Outro indicador forte do conhecimento do mundo da educação é dado pela ciência das atividades extracurriculares: quando se sabe o que a instituição propõe para os filhos, fica mais fácil motivá-los a participar e/ou a cobrar a participação. Assim o conhecimento da escola dos filhos é um forte indicador de que essas mulheres atravessaram o portão da escola e visitaram o que está dentro do sagrado universo do saber (talvez porque elas próprias já o fizeram como alunas, contrariamente às suas próprias mães).

Por fim, frisamos que o engajamento dessas famílias na transmissão do capital escolar para os filhos é sem dúvida um fator explicativo de nossa questão. Pierre Bourdieu nos ensina que as classes populares precisam "pelo menos" estar comprometidas "no processo educativo" para que consigam reconhecer "seu interesse de classe em matéria de educação" (BOURDIEU, 1979, p. 452). A mãe que se investe ou tem um parente próximo (filho mais velho ou tios do aluno), empenhado em ajudar o estudante em suas tarefas escolares, tem maior probabilidade de cumprir a condicionalidade do PBF.

\section{REFERÊNCIAS}

ALVES, J. E. D., CAVENAGHI, C. O Programa Bolsa Família e as taxas de fecundidade no Brasil. In: CAMPELLO, T.; NERI, M. C. (Orgs.). Programa Bolsa Família: uma década de inclusão e cidadania. Brasília: Ipea; MDS, 2013. 87 p. 
BOURDIEU, P. La distinction: critique sociale du jugement. Paris: Les Éditions de Minuit. 1979. (Le sens commum).

BRASIL. Acompanhamento da condicionalidade da educação do PBF: gestão 2011 a 2014. Brasília: Ministério da Educação, 2014a.

BRASIL. Curso de Especialização em Educação, Pobreza e Desigualdade Social. Projeto Político Pedagógico. Brasília: MEC - SECADI. 2014b.

CARLOTO, C. M. A chefia familiar feminina nas famílias monoparentais em situação de extrema pobreza. In: Revista Virtual Textos e Contextos, Rio Grande do Sul, v. 4, p. 01-17, 2005. Disponível em: <http://revistaseletronicas.pucrs.br/ojs/index.php/fass/ article/viewFile/994/774>. Acesso em: 10 nov. 2008.

DE WITTE, K. et al. A critical review of the literature on school dropout. Educational Research Review, 10, p. 13-28, 2013.

LEÃO REGO, W.; PINZANI, A. Vozes do Bolsa Familia: autonomia, dinheiro e cidadania. 2. Ed. São Paulo: Editora Unesp, 2014.

LEE, V. E., BURKAM, D. T. Dropping out of high school: The role of school organization and structure. American Educational Research Journal, 40 (2), p. 353-393, 2003.

MARKS, G., FLEMING, N. Early School Leaving in Australia: Findings from the 1995 Year LSAY Cohort. Research Report. ACER. 1999.

OLSEN, R.J., FARKAS, G. Endogenous Covariates in Duration Models and the Effect of Adolescent Childbirth on Schooling. Journal of Human Resources, v. 24, n. 1, p. 39-53, 1989.

PITTMAN, R. B. Social factors, enrollment in Vocational/Technical courses, and high school dropout rates. The Journal of Educational Research, v. 84, n. 5, p. 288-295, 1991.

RUMBERGER, R.W. Why students drop out of school. In: ORED, G. (Ed.). Dropouts in America: confronting the graduation rate crisis. Cambridge, MA: Harvard Education Press, 2004.

SILVEIRA, F.G., CAMPOLINA B., VAN HORN, R. Impactos do Programa Bolsa Família na alocação do tempo entre escola e trabalho de crianças e adolescentes de 10 a 18 anos. In: CAMPELLO, T.; NERI, M. C. (Orgs.). Programa Bolsa Família: uma década de inclusão e cidadania. Brasília: Ipea; MDS, 2013.

Texto recebido em $1^{\circ}$ de junho de 2017. Texto aprovado em 10 de junho de 2017. 
